Continental Shelf Research

March 2018, Volume 155 Pages 11-20

http://dx.doi.org/10.1016/i.csr.2018.01.010

http://archimer.ifremer.fr/doc/00423/53457/

(C) 2018 Elsevier Ltd. All rights reserved.

\title{
The boundary current role on the transport and stranding of floating marine litter: The French Riviera case
}

\author{
Ourmieres Yann ${ }^{1,}{ }^{*}$, Mansui Jérémy ${ }^{1}$, Molcard Anne ${ }^{1}$, Galgani François ${ }^{2}$, Poitou Isabelle ${ }^{3}$
}

${ }^{1}$ Univ Toulon \& Var, MIO, IRD, INSU,CNRS,UMR7294,UM 110, F-83957 La Garde, France.

2 IFREMER, ZI Furiani, Immeuble Agostini, F-20600 Bastia, Corsica, France.

${ }^{3}$ Assoc Mer Terre, 21 Rue Montgrand, F-13006 Marseille, France.

*Corresponding author : Yann Ourmieres, email address : yann.ourmieres@univ-tln.fr

\begin{abstract}
:
The aim of the present study is to evidence the role of a boundary current and meteorological conditions in the transport and stranding of floating marine debris. The used data are from a beach survey and an inter-annual unique effort of marine debris sightings along the French Riviera in the North-Western Mediterranean region. Offshore data have been collected during oceanic cruises while beach surveys were performed around Antibes city. Debris were found on $97 \%$ of the ocean transects, with a large spatial and temporal variability, showing contrasted areas of low ( 1 item/km2) and of high (> 10 items $/ \mathrm{km} 2$ ) debris densities. Results suggest that the debris spatio-temporal distribution is related to the Northern current (NC) dynamics, the regional boundary current, with accumulation patterns in its core and external edge. By playing a role in the alongshore transport, such a boundary current can form a cross-shore transport barrier. Stranding events can then occur after strong on-shore wind bursts modifying the sea surface dynamics and breaking this transport barrier. It is also shown that episodic enhancement of the stranding rate can be explained by combining the NC dynamics with the wind forcing and the rainfall effect via the local river run-off. Conversely, off-shore wind bursts could also free the marine litter from the boundary current and export them towards the open sea.
\end{abstract}

\section{Highlights}

- Role of a boundary current in the transport and stranding of floating marine debris. The boundary current forms a cross-shore transport barrier. Stranding events can occur after strong on-shore wind bursts. Off-shore wind bursts can also export the marine litter towards the open sea. The wind forcing and the river run-off modify the boundary current role. 


\section{Introduction:}

Floating marine debris (FMD hereafter) is nowadays recognized as one of the most pervasive problems affecting the marine environment. This growing danger for the ecosystems (Gregory, 2009) mainly results from a perpetual and worldwide production increase of plastic items, which account for a majority of the floating debris encountered at sea (Derraik, 2002 ; UNEP, 2009). Several studies have demonstrated the existence of large-scale accumulation regions of plastic debris in the oceans (Kubota, 1994; Moore et al., 2001), with materials gathering in convergence zones corresponding to subtropical gyres. High abundances of FMD were further reported in many regions of the world, particularly in semi-enclosed seas associated to densely populated coastal areas. In this context, the Mediterranean Sea has been identified as one of the most important accumulation zone in the world (Lebreton et al., 2012 ; Eriksen et al., 2014 ; Cózar et al., 2015). It is however worth noting that most studies have been performed for small sized particles, and that it is not necessarily true that large and small to very small particles follow the same paths during the accumulation process.

The first observation of plastic debris floating in the Mediterranean waters (south west of Malta) was reported by Morris (Morris, 1980) and is associated to an abundance of approximately 1300 items $/ \mathrm{km}^{2}$. This very high value should be considered cautiously as the observation was based on a single quantitative visual survey of one hour. Since then, various studies have shown that the Mediterranean basin is impacted in various degrees by FMD. In the eastern Mediterranean Sea, two previous surveys (Mc Coy, 1988 ; Topçu et al., 2010) on large FMD, that were visually observed, reported estimates of FMD densities lower than 2.5 items $/ \mathrm{km}^{2}$. A first large-scale survey using the same methodological approaches in the central and western parts of the Mediterranean Sea was 
carried out by Suaria and Aliani (2014). Observed mean densities were in this case about one order of magnitude higher (mean densities of 24.9 anthropogenic marine debris $/ \mathrm{km}^{2}$ and 6.9 natural marine debris $/ \mathrm{km}^{2}$ ), with a great variability. These latest observational studies converge to a similar order of density, but it must be kept in mind the difficulty in merging them as survey methods are never identical. In this sense, the data used in the present study are not treated as strictly quantitative observations as absolute numbers might be argued. However, we use consistent methodologies and our data set has a robust repeatability. For instance, we consider that the numbers are less important than the difference between two neighbouring observation sites.

On the numerical side, Lebreton and co-workers were first to actually model the transport and distribution of floating debris in the Mediterranean Sea (Lebreton et al., 2012). In this global scale simulation, between $6 \%$ and $8 \%$ of the particles introduced in the model were finally retained by the Mediterranean basin. A total plastic load in the basin of 23.150 tons (surface) has been subsequently estimated by Eriksen et al. (2014) thanks to a calibration of this model using a global data set. However, one needs to be cautious about such calibration of model distribution since low agreement was found between measurements and model predictions. A recent estimate made by Cózar et al. (2015), and based on a set of 72 net tows analysed with a gridded approach, is indeed one order of magnitude lower.

Mansui et al. (2015) also proposed in another modelling paper a schematic view of the general behaviour of marine debris in the Mediterranean Sea, with three potential non-permanent aggregation zones. Two of these zones, namely the north-western and Tyrrhenian sub-basins, appear as a result of the rotating behaviour of the general surface circulation, while the third aggregation zone, near the gulf of Sirte, is probably due to the weak dynamics of the area. Some visual surveys confirmed the presence of high debris densities in these potential aggregation zones, such as the campaigns conducted by Suaria and Aliani (2014) in the north-western and Tyrrhenian zones.

We assume that part of the FMD from these aggregation areas can be transported over long distances by surface circulation and can supply the Ligurian Sea and the French Riviera. High debris densities have been already observed in the Ligurian Sea from 18 shipboard surveys (Aliani et al., 2003a, 2003b) and a global aerial campaign over the north-western sub-basin (Pettex et al., 2014), but a strong spatio-temporal variability in the local concentration of debris was also reported. Aliani et al. (2003b) suggested that different meteorological conditions were responsible for the variability observed during shipboard surveys. Such an accumulation of floating debris is also likely related to local urban discharges and river outflows.

In the Ligurian Sea, and more generally in the north-western sub-basin, the major oceanographic feature of the surface layers is a permanent coastal-density current named the Northern Current (NC) (see section 2.1). This current has recently been identified by Berline et al. (2013) as the main driver for the alongshore transport of jellyfish (Pelagia noctiluca). The Pelagia distribution in time and space depends on the interplay between population dynamics and dispersal by currents. A NC position close to the coast and the presence of alongshore winds are the key factors underlying major arrivals of jellyfish on the beaches (Berline et al., 2013). Since Pelagia is mainly transported by horizontal currents, its fate may be comparable to the transport of FMD. Consequently, the NC may also affect the transport of marine litter along the French Riviera, as well as stranding events.

The objective of this paper is to study the role of the NC and the meteorological conditions in the transport and stranding of FMD. Our approach is based on the analysis of an original data set of ship sightings and stranding surveys. This is the only data set in western Ligurian Sea merging visual observations (offshore) and collected items (beaches). A similar approach approach has been used by Thiel et al. (2013) in Chilean coastal waters to reveal the spatio-temporal dynamic of anthropogenic marine debris and to identify the main sources of this debris in the study area.

\section{Materials and methods:}

\subsection{Study area:}


The study area is the western Ligurian Sea extending westward to the French Riviera and southward to the Corsica island (Fig. 1). An uneven bathymetry can be found at the northern part of the area, with a continental shelf very narrow and an abrupt continental slope close to the coast. The surface layers are characterized by a predominant circulation pattern, the NC, resulting from the merging of the Eastern Corsican Current (ECC) and the Western Corsican Current (WCC). This circulation flows westward along the shelf (Millot, 1999), being topographically guided by the 1000 $\mathrm{m}$ isobath, and follows the French coast from the Ligurian Sea down to the Spanish coast as part of the general cyclonic circulation of Mediterranean waters in the western basin. The NC behaviour in the area is well understood and widely documented in terms of trajectory, magnitude (Bethoux et al., 1982 ; Taupier-Letage and Millot, 1986 ; Albérola et al., 1995) and spatio-temporal variability (Sammari et al., 1995 ; Guihou et al., 2013). The NC is characterized by a strong seasonal variability and mesoscale activity. In summer, a quite steady and weak flow $(<0.5 \mathrm{~m} / \mathrm{s})$ can be observed with a width around $40 \mathrm{~km}$ (Albérola et al., 1995 ; Conan and Millot, 1995). The NC onshore branch can be located as far as $40 \mathrm{~km}$ away from the coast (Niewiadomska et al., 2008 ; Ourmieres et al., 2011). In winter, a stronger ECC leads to an acceleration of the NC (surface velocities up to $1 \mathrm{~m} / \mathrm{s}$ ) (Taupier-Letage and Millot, 1986 ; La Violette et al., 1994), a narrowing (25 $\mathrm{km}$ ) and a position closer to the coast (around $5 \mathrm{~km}$ ). The alongshore general circulation of the NC is not favourable to a cross-shore transport of floating marine debris to the coastal zone. Nevertheless, the strong mesoscale activity associated to the current instabilities leads to the generation of meanders or eddies, especially in winter (Millot, 1999) but not only (Guihou et al., 2013). In such particular cases, the NC can occasionnally transfer offshore waters to the coast, but this aspect has been more evidenced downstream (in the Gulf of Lions) than along the French Riviera (Barrier et al., 2016). Finally, episodic wind bursts in the alongshore direction can move the NC to the coast (Berline et al., 2013), also inducing an intense, but temporary, cross-shore transport in surface.

\subsection{Observations:}

Large FMD and stranded debris were respectively sampled in the framework of the participative science activities of EcoOcean Institute (www.ecoocean-institut.org) and Mer-Terre association (www.mer-terre.org). Observations were carried out respectively between 2006 and 2008 (ecoocean) and in 2010 (mer-terre) with specific protocols described hereafter. The gathering and the analysis of this data set represent the only attempt so far for the study area to describe the spatial distribution of large FMD in semi-quantitative terms (see below), as well as stranding events using a qualitative approach.

The data set on FMD was collected for the Marine Strategy Framework Directive (MSFD) initial assessment (Gerigny et al., 2011). It is contituted of 801 counts along 67 transects performed between years 2006 to 2008. It gathers multiple days of observations for several months during this interval, but with no regular periodicity. The method was based on the principle of strip transect (Buckland et al., 2001) without strip-width modelling but real counts related to surfaces covered between 2 positions calculated from GPS starts and stops. Observations and related distances of debris were initially validated during preliminary experiments using parametric binoculars. These experiments allowed the EcoOcean team to define a total bandwidth of $100 \mathrm{~m}$, stalling on a bandwidth of $50 \mathrm{~m}$ on each side of the strip, as controlled by binoculars, that enabled a consistent discrimination of all floating debris. Subsurface debris were not considered in the assessments. Sightings were performed only under calm seas (wind speed $\leq 2$ Beaufort) in order to minimize the effect of the wind-induced vertical mixing of the marine debris, and at a speed around $6( \pm 0.5)$ knots. Visual observation of surface synthetic debris was focused on large objects, without consideration of small (less than $5 \mathrm{~cm}$ ) debris or their colours. Three observers from the bearing deck covered continuously a $180^{\circ}$ range in front of the ship. Unfortunately, the size of each litter and perpendicular distances from the observer were not recorded, but Suaria et al. (2014) have 
shown that the size of the majority of anthropogenic marine debris, visually observed with the same methodological approaches in the central and western parts of the Mediterranean Sea, is between 10 and $50 \mathrm{~cm}$. Data from each observer cannot be considered here as replicates because only the total number of floating marine debris observed during each count is available. Acknowledging this potential source of error in the data set, the present work will focus on large spatial-temporal gradients rather than on a strictly quantitative use, thus reducing possible misinterpretations. Other variables that could impact visibility (e.g. rain) or detectability (e.g. shape) of debris were ignored because surveys occurred during daylight hours under good weather conditions, only when the detection probability within the transect width was not compromised. The survey effort (transects) was split into 30-min sections (mean length around $5 \mathrm{~km}$ ), each of them being associated with one mean position (calculated from GPS starts and stops) and a debris density $d$ given in items $/ \mathrm{km}^{2}$, representative of the local debris distribution observed in the section. The density $d$ is expressed as $d=\frac{n}{W \cdot d i s t}$ section, and $n$ the total number of items observed inside the surveyed bandwidth. The gathering of these multiple transects will then be used to infer the general spatial distribution of FMD in the covered area. Additional information on the dataset can be found in a recently published work from Di-Méglio and Campana (2017), for which a larger dataset has been used but includes the one presented in our study.

Concerning beach surveys, observations of marine litter stranded on 3 beaches of Antibes (Fort Carré, Ponteil and La Salis) were carried out by the technical department of the city from June 1 to 27 (2010), using a method defined by the Mer-Terre association. Figure 2 shows the local coastline set up and indicates the beaches locations. The global situation of these beaches along the French Riviera can be found on figure 3 (indicated by a black star along the coastline). Litter collection was manually performed every day, between 6 and 8 in the morning, by 10 municipal officers in order to estimate the daily intake of synthetic stranded items in terms of volume. The approach used here is not intended to make an accurate evaluation of daily volumes, as several tens or hundreds of cubic meters can strand on each beach in one day during a major event, but rather to assess an order of magnitude of these volumes. The timing of sampling was not tied to tidal cycle because the Mediterranean Sea is a microtidal sea (tidal range of $20.8 \pm 5.6 \mathrm{~cm}$ in the sampled sites). The survey effort can be then be assumed as continuous over time. Litter was picked along a 3-m strip from the shoreline with the aim to only collect stranded waste. The sampled section was $2450 \mathrm{~m}$ in length, for a total sampled area of $7350 \mathrm{~m}^{2}$. The daily volume of stranded litter picked on the beaches was estimated from the total volume of trash bags used to enclose all collected items. Items were sorted in 4 categories (plastic, wood, seaweed and others) before being stuffed in trash bags (only for the plastic item category). Very small items (e.g. resin pellets) were not considered, and centimeter scale items were recorded only when they were identifiable to the naked eye (e.g. cigarette butts or bottle caps). Generally, every collected items in the plastic category could easily be enclosed in trash bags. No awkwardly or very large shaped items were encountered, in such a way that the volume of items which are stuffed in a trash bag may be approximated by the volume of this bag, even if some empty space still exists. It must be kept in mind that the goal is to identify major stranding events, involving huge volumes of stranded items, and to relate them to the ocean dynamics and meteorological conditions.

\subsection{Numerical tools:}

The position of the NC and its dynamics were inferred from an Oceanic General Circulation Model (OGCM) and compared to the FMD observations. The model used is the Nucleus for European Modelling of the Ocean (NEMO) (Madec, 2008) in a realistic regional high-resolution configuration (GLAZUR64, Ourmieres et al., 2011) over the gulf of Lion and the western Ligurian Sea $\left(2.09^{\circ} \mathrm{E}-7.97^{\circ} \mathrm{E}, 41.26^{\circ} \mathrm{N}-43.90^{\circ} \mathrm{N}\right)$. The numerical model solves the primitive equations assuming the hydrostatic equilibrium, the Boussinesq approximation and a free surface formulation. 
Adaptative boundary conditions (Cailleau et al., 2008 ; Guihou et al., 2013) and free slip conditions are respectively used at the open boundaries and the coast. The resolution on the horizontal is $1 / 64^{\circ}$ on a regular mesh. The vertical dimension is unevenly spaced with $130 \mathrm{Z}$-levels from the surface $(\Delta \mathrm{Z}=1 \mathrm{~m})$ down to the bottom $(\Delta \mathrm{Z}=30 \mathrm{~m}) .43$ levels are in the first $100 \mathrm{~m}$ to better represent the upper boundary layer. The atmospheric data used to force the GLAZUR64 configuration comes from the Météo-France (the French weather forecast center, www.meteofrance.com) operational regional model ALADIN and is available every 3-hr on a $9.5 \mathrm{~km}$ by $9.5 \mathrm{~km}$ grid. This meteorological model includes data assimilation and generally provides a valid picture of the meteorological regimes in the north-western Mediterranean Sea (Herrmann et al., 2011). The oceanic open boundaries are provided by the NEMO PSY2V4R4 Mercator-Ocean simulations (http://www.mercator-ocean.fr). Previous studies (Ourmieres et al., 2011 ; Guihou et al., 2013) have shown that the GLAZUR64 configuration realistically simulates the NC mesoscale variability. The model dynamics include the Ekman drift, the baroclinic motion, the inertial currents as well as the Stokes drift induced by waves. Ourmieres et al. (2011) showed that such a configuration is suitable for coastal process studies. Here, we have only considered the surface velocity fields over two periods, from October 2006 to October 2008 (shipboard observations) and in June 2010 (stranding surveys).

The Finite Time Lyapunov Exponents (FTLEs) (Haller and Yuan., 2000 ; Tallapragada and Ross, 2013) have also been calculated in this paper using June 2010 velocity fields (GLAZUR64), and with a 6-day integration time, to study the transport dynamics due to the NC, possibly linked to the FMD stranding dynamics. The FTLEs are a useful tool to identify transport barriers defined by Lagrangian Coherent Structures (LCSs, see for example (Haza et al., 2007 ; Haller, 2011)), i.e. ridges of FTLEs. They measure the average local stretching around reference trajectories and provide a simplified and integrated skeleton of the overall dynamics of the system. This Lagrangian metric exploits both spatial and temporal variability of a given field, and highlights regions with different dynamical behaviour, detecting avenues and barriers to transport. Computations were performed here using the OceanFTLE Matlab package written by D. L. Volkov.

\subsection{Hydrological and satellite data:}

The NC position relative to the coast has also been inferred from Sea Surface Temperature (SST) satellite data because of its thermal signature different from the neighbouring waters. The data set used is the SST product from the MyOcean-2 project (www.myocean.eu) and corresponds to daily reprocessed maps of the Mediterranean Sea at high resolution (Level 4 products at $0.04^{\circ}$ resolution, refer to Buongiorno Nardelli et al. (2013) for further details). However, the major limitation of this method occurs for episodic wind bursts such as strong westerlies, very typical in the region, that cool the surface and avoid NC detection. Nevertheless, shipboard observations could only be carried out with a calm sea state condition excluding any major wind burst, so that a comparison between FMD locations and NC position can be considered in the majority of cases. Nevertheless, at-sea surveys have been sometimes carried out after a wind event, when the NC thermal signature is not yet visible. In this particular case, SST maps were not used for the analyses.

SST maps were coupled to model outputs velocity maps to get the best possible confidence in the $\mathrm{NC}$ vein position. The FMD locations were then compared to the envelope of westward alongshore velocities superior to $20 \mathrm{~cm} / \mathrm{s}$ and SST gradient. Finally, daily averaged run-off of the Var river and 3-hour rainfall (from the ALADIN model) were used in order to assess the potential role of the river in these events. Run-off data were produced by the "Direction Régionale de l'Environnement et Aménagement du Logement” (DREAL) PACA and are freely available via www.hydro.eaufrance.fr/.

\section{Results:}

\subsection{Coastal and offshore debris distribution:}


FMD were observed on $97 \%$ of the transects with a very high spatial and temporal variability, with densities ranging from 0 to about 51 items $/ \mathrm{km}^{2}$. Although the sightings protocol has been thouroughly prepared, it is however impossible to consider it as fully quantitative, as already stated in section 2.2: sighting errors are inevitably present and the protocol itself, although covering a large area and a long period cannot be considered as fully representative due to its spatial and temporal scattering. The following results are then based on indicators such as high or low occurrence instead of relying on the absolute numbers. However, all observations are listed in table 1 , provided as supplementary material.

Relatively high abundances of floating debris were recorded from May to June 2007 and 2008 as well as during October 2008, when compared to the other months of the survey: maximum FMD densities were very frequently recorded higher than 10 items $/ \mathrm{km}^{2}$ and up to 51 items $/ \mathrm{km}^{2}$ when most of the sightings period were significantly lower, around 1 item/ $\mathrm{km}^{2}$. Figure 3 shows these results and highlights these facts by differentiating area of low densities $\left(<10\right.$ item/ $\left.\mathrm{km}^{2}\right)$ and of high densities ( $>10$ items $/ \mathrm{km}^{2}$ ). Hence, the contrast being large enough, the results can be exploited to provide information on the spatial and temporal FMD dispatching. Low FMD densities were mostly observed near the coast or very far offshore, while high densities were simultaneously found on the NC external edge, 20 to $40 \mathrm{~km}$ from the coast (Fig. 4). This result significantly differs from the coastal-offshore increasing trend of micro-plastic reported in previous papers for this area (Pedrotti et al., 2016) or in other regions (Thiel et al., 2003, 2013).

If the FMD observations and the simulated NC general position are superimposed (Fig. 3), it appears that about $75 \%$ of high debris densities are located inside the NC general path or in the immediate vicinity of its external edge. The accuracy of the NC position during daily shipboard observations was improved by comparing the positions of the FMD counts to composite maps created by superposing the corresponding daily GLAZUR64 circulation outputs to the daily satellite SST maps. More precise NC path daily positioning and accurate spatial-temporal matching between the local ocean dynamics and the FMD distribution were obtained. A review of all these maps shows that two constrasting scenarios come out.

The first typical case corresponds to high debris densities found inside the boundary current path: $67 \%$ of the total transects have been performed in the NC path vicinity, and among these transects, $78 \%$ of them showed a high debris density. The NC path area has been defined as the envelope of westward alongshore velocities superior to $20 \mathrm{~cm} / \mathrm{s}$, according to Guihou et al. (2013). Only a few transects cross totally the NC from the coast to the open sea, but $66 \%$ of them show a gradual increase of debris density when moving off shore. In such cases, the NC external front appears to be the preferred area for debris accumulation, as can be observed for example in October 2006 (Fig. 5a).

The second typical case corresponds to high debris densities in offshore waters and low debris densities between the coast and the NC external edge as shown for example in (Fig. 5b): this case represents $18 \%$ of all the transects. It appears that most of these cases can be explained by their recent meteorological and hydrological history. For example, a strong offshore wind (Mistral) occurred in May 2007, one week before the FMD surveys (Fig. 6b). With a wind speed ranging from 10 to $15 \mathrm{~m} / \mathrm{s}$, this Mistral event is sufficiently long and strong to impact the surface currents and export floating marine debris to offshore locations. When examining the wind conditions one week before all offshore observations of litter, it appears that seven out of the twelve affected transects have been actually preceded by such an offshore wind regime. Conversely, transects with a maximum debris density located on the NC external edge are not preceded by strong offshore winds (e.g. in October 2006, Fig. 5a for the FMD density and Fig. 6a for the wind conditions), or these short offshore wind events are directly followed by onshore winds. It can also be inferred that the remaining unexplained cases with high debris density spots located far offshore are probably linked to the same kind of transport dynamics but maybe with a strong unsteady meteorological conditioning, making difficult to trace back their journey. However, the frequency and the average strength of the offshore winds in the area, the Mistral, lead us to think that this offshore export of 
floating debris is realistic. This assertion is also strengthen by observations (not published) of the surface current obtained by HF radar measurements in a coastal portion of the area (see Marmain et al. , 2014 for the HF radar set up) . These data show that in the case of a significant Mistral event, the NC surface layer, flowing more or less westward, disappears and a strong offshore southeastward surface current sets in during the wind burst. This strong temporary surface current can then be supposed to be responsible for the FMD export far off the coast.

\subsection{Litter stranding:}

In June 2010, a low stranding rate of floating marine litter was recorded during the entire month at the three sampled sites (0-4 m³/day), apart from June 11 (E1 event) and 16 (E2 event) for which total volumes of collected items are one order or two orders of magnitude higher than during the rest of the month (Fig. 7). The debris volumes collected each day on the beaches, excluding these two events, are very low in regard to the surveyed beach section while the touristic beach use remains in general very high. So, we assume that only specific ocean and/or weather conditions can be responsible for these distinctive stranding events. A strong and moderate easterly wind event is evidenced on Fig. 8 before E1 and E2 respectively. The first wind event appears to be twice longer than the second (48h vs $24 \mathrm{~h}$ ). This is an important point to make because the total volume of collected debris at the three sites during E1 is higher too. So, in order to determine to what extent easterly winds do affect the dynamics of the surface currents, FTLEs were calculated for the beach survey period (Fig. 9). It is recalled that the FTLE calculation allows to identify LCSs corresponding to the studied flow: these structures help identifying transport barriers in the velocity field (dark contours in fig. 9). The LCSs observed before (Fig. 9a), between (Fig. 9d, 9e and 9f), and after (Fig. 9h and 9i) the easterlies are associated to alongshore lines, suggesting that the NC is playing the potential role of a cross-shore transport barrier. This is not the case during easterlies (Fig. 9b, 9c and 9g), for which LCSs are different: alongshore lines bend and become clearly crossshore oriented. In these particular cases, it can be assumed that the appearing cross-shore component of the velocity field is likely to favour the stranding events. This combined action, coupled with the orientation of the coast, enhances the stranding of marine litters and can be considered as the main reason why a huge amount of debris was collected on Antibes beaches, on June 11 and 16. A similar offshore shift of the NC can also be observed during meander or eddy events as can be seen on figure 10, showing the time-latitude evolution of the surface current. However, LCSs are not necessary cross-shore oriented in this case, which can explain the fact that no major stranding event occurred starting from June 23, whereas the NC moves closer to the coast due to the appearance of a meander in front of Antibes.

Hence, it can be inferred that at such a scale, the NC, acting as a FMD carrier (and collector), is a dominant actor in the presented cases of massive FMD stranding events on the surveyed beaches. However, additional elements show that local factors such as the river run-off can also have to be accounted for. Indeed, the change in the surface dynamics allowed by the easterly wind event in June 15 (Fig. 8) might not be the only reason for the second stranding event (E2). The wind effect on the NC is actually less intense during E2, with a NC core far away from the coast, than it is before E1 from June 9 to 10. GLAZUR64 simulations also show a very strong secondary onshore branch flowing westward before E1 (Fig. 10), that totally disappears before E2, and a faster change of LCSs can be deduced from the FTLE snapshots (Fig. 9b, 9c and 9g). Nevertheless, the collected debris volumes were of the same order of magnitude during both stranding events. There are two possible explanations for this: first, the density of floating marine debris transported by the NC is higher during the second event, and counterbalances the shortness of the easterly wind event. Second, there is a possible dramatical increase in the input of a local source of marine debris. In this sense, the Var river, located $10 \mathrm{~km}$ from the sampled sites, with its mouth directly facing them (Fig. 2 ), is the second most important French Mediterranean river in terms of annual water flow rate. Its particular situation in a densely-populated area makes this river a significant actor for the transportation of debris, in particular during strong rainfall leading to important soil leaching. 
Several accumulation areas on the deep sea floor were already located in front of the Var mouth by Galgani et al. (1996) who analysed various diving observations in canyons located off the Nice area. More generally, a previous study conducted in southern California has already demonstrated that plastic quantity flowing in urban rivers are significantly higher during wet periods (Moore et al., 2011). For our case, an analysis of the meteorological conditions in June 2010 shows that only one strong rainfall event was recorded during the 15th-16th night and has impacted the Var river watershed (Fig. 11). This rainfall event is connected to a sudden increase in the Var river run-off, as evidenced by looking at the daily average run-off on June $16\left(172 \mathrm{~m}^{3} / \mathrm{s}\right)$, twice higher than the monthly average $\left(91 \mathrm{~m}^{3} / \mathrm{s}\right)$. Because the debris collection on this day directly followed the storm, and the river location is upstream of the three surveyed beaches, the Var river must be considered as another important source of marine litter during the second stranding event. But again for E2, the coastal dynamics conditioned by the easterlies were favourable for the trapping of debris along the coast and not for an export off-shore, as a Mistral event could do. Hence, even if for E2 the main source might be the coast and not the NC, it can be assumed that the boundary current can also indirectly impact the fate of the floating debris.

\section{Conclusion:}

In the present work, a boundary current was identified as the main factor affecting the coastal distribution of FMD. The proximity of land-based sources, linked to densely populated zones, appears in this particular case as a secondary factor since the mesoscale activity of the boundary current prevents long-term accumulation of macro-debris in the 10-km water strip adjacent to the coast (accumulation previously reported by Thiel et al. (2003) in South-East Pacific).

This is the first attempt to study the transport and stranding of FMD in a general boundary current context, but also in the Mediterranean Sea, from a data set composed of at-sea and shore-based observations. Despite a scattered distribution in time and space of the shipboard observations as is frequently encountered in such data, this data set is currently the only one in this part of the Mediterranean Sea with such a spatio-temporal coverage. Our approach, based on the study of the NC case, was designed to highlight the role of a boundary current and the meteorological conditions on the spatial distribution of floating marine litter in coastal areas and the triggering of major stranding events. It could be applied similarly in other areas since the dynamic of the NC, the weather forcing and offshore/coastal water exchanges can be found in numerous coastal to regional ocean areas. Mistral and easterly winds are the predominant wind regimes encountered along the French Riviera coastline. Previous studies (Bethoux et al., 1982 ; Berline et al., 2013 ) have shown that these wind regimes interact strongly with the ocean surface, in particular with the NC. Berline et al. (2013) already evidenced that jellyfish stranding in Nice (18 km west to Antibes) are greatly influenced by the NC position and the alongshore wind (i.e. easterly winds). Jellyfishes follow the $\mathrm{NC}$ flow and can be carried in the surface layer by Ekman currents, oriented $45^{\circ}$ to the right of the wind direction, which are directed onshore for north-easterly winds. A similar interaction between easterly wind events and FMD stranding can be assumed here, and has been already demonstrated in other areas in the world (Vauk and Schrey, 1987 ; Galgani et al., 2000 ; Thiel et al., 2011), even if the NC role in the alongshore transport was not considered.

The EcoOcean data set cannot be fully considered as quantitative for protocol reasons . It has then been used with care regarding this issue, focusing on large spatial and temporal variations instead of local density alone. However, the densities of FMD observed during the EcoOcean cruises are typical of this part of the Mediterranean Sea according to the few other campaigns of large debris visual surveys, conducted in the Ligurian Sea in 1997 and 2000 by Aliani et al. (2003b), and showing mean debris densities between 1.5 and 25 items $/ \mathrm{km}^{2}$, despite not using a perfectly similar protocol. On a larger spatial scale, Suaria and Aliani (2014) reported observations based on a comparable methodological approach in the western Mediterranean Sea with debris densities one 
order of magnitude higher. Such a difference in the detection rates can mostly be explained by the spatial heterogeneity of marine litter distribution, and to a lesser extent, by the experimental conditions. Although shipboard surveys were made in both cases by scanning the sea surface during the same seasons, they were also done from various research vessels with different deck heights, which could indeed affect the detection rate.

Locations of high debris densities are generally found in good agreement with the NC path and indicate that the distribution of floating marine debris off the French Riviera is strongly conditioned by this permanent circulation pattern. It has however to be reminded that observations were made during good weather conditions, i.e. not during strong easterly winds that could have pushed the NC on shore, possibly leading to an input of FMD along the coast. It is interesting to note that the recent sampling of micro-plastics in the region by Pedrotti et al. (2016), combined with data previously reported for the Mediterranean Sea (Lucia et al., 2014 ; Cózar et al., 2015), did not show a similar pattern, but rather the presence of high micro-plastic densities in the 1-km water strip adjacent to the coast and in distant waters (around $100 \mathrm{~km}$ ). No accumulation of micro-plastics in the NC path was observed by this study, maybe as a result of the very few observations carried out inside the NC. This antinomic results might point here again the fact that FMD and micro-plastic do not behave similarly in oceanic currents.

Several observations of high debris densities were also directly reported near the external front. The fact that high abundances of marine debris were encountered in a frontal zone is another interesting point. The only other study on this topic was conducted by Acha et al. (2003), who reported the efficiency of the Rio de la Plata (South America) bottom salinity front in trapping marine debris. This should be investigated in future works as frontal zones are very sensitive areas hosting a high biological productivity induced by vertical transfers of nutrients (Boucher et al., 1987 ; Niewiadomska et al., 2008). For instance, Ferraris et al. (2012) have observed, during repeated campaigns, the regular increase of Pelagia noctiluca jellyfish distribution from the coast to the NC external front.

Offshore high debris densities were sometimes also encountered far away from the NC external edge. Analyses of the meteorological condition history before each of these observations show that Mistral events (blowing seaward) can be seen as a reasonable hypothesis for the offshore export of FMDThe FTLE fields confirm this hypothesis, as well as verifying the fact that such a boundary current is playing the role of a cross-shore transport barrier under calm sea conditions. Another reason could be found in the Mediterranean mesoscale dynamics, such as NC large meanders (Albérola et al., 1995 ; Sammari et al., 1995) or eddies (Rubio et al., 2005 ; Guihou, 2013), even if none of these physical processes were observed on modelled velocity fields or SST maps during the EcoOcean cruises.

The stranding of floating marine litter along the Antibes coastline can be explained by the quasipermanent presence of marine debris in the NC branch, at least during summer, combined with onshore easterly wind bursts, and potentially modulated by land-based inputs from the Var river. In this case, strong wind bursts alter the sea surface dynamic in such a way that the usual alongshore transport of FMD induced by the boundary current actually gives way to a strong cross-shore component of the surface velocity allowing stranding events. It should however be kept in mind that small scale coastal currents, not modelled by the GLAZUR64 configuration due to its resolution, were not considered in this study and can also partly explain stranding events, together with the possibility of a temporary high density mixture of debris in the water close to the coast that moves in and out of the beaches daily.

Finally, further studies are required to improve our understanding of all these transport mechanisms in coastal areas impacted by the presence of a boundary current. For instance, high debris densities were reported in May/June 2007 and 2008 during the EcoOcean cruises, possibly suggesting variations in the number of floating marine debris transported by the NC, but the data set of shipboard observations is not robust enough to adequately study this process. More consistent observation campaigns are in fact required. Such campaigns should include regular transects throughout the year, and not only during the summer to autumn season, giving priority to transects 
that cross the boundary current branch. Continuous beach surveys should also be carried in parallel to shipboard observation periods with a daily frequency during bad weather conditions and with a 1-week or 2-week frequency during low wind conditions, when the stranding of floating marine debris is generally lower. Such an approach will provide the advantage of minimizing the number of beach surveys while targeting the potential interesting events.

\section{Acknowledgements:}

The calculations were performed using the GENCI-IDRIS resources (Grant 2014011707). The authors also wish to thank Mercator Océan and Météo-France for providing numerical data, MyOcean-2 project for the SST data, the EcoOcean Institute for the data provided to F. Galgani in the framework of the MSFD, and finally Veolia and the technical services of the municipality of Antibes for the collection of stranding data supplied to I. Poitou.

\section{References:}

Acha, E. M., Mianzan, H. W., Iribarne, O., Gagliardini, D. A., Lasta, C., Daleo, P., 2003. The role of the Rio de la Plata bottom salinity front in accumulating debris. Marine Pollution Bulletin 46(2), 197-202.

Albérola, C., Millot, C., Font, J., 1995. On the seasonal and mesoscale variabilities of the Northern Current during the PRIMO-0 experiment in the western Mediterranean Sea. Oceanologica Acta 18, 163-192.

Aliani, S., Molcard, A., 2003a. Hitch-hiking on floating marine debris: macrobenthic species in the western Mediterranean Sea. Hydrobiologia 503, 59-67.

Aliani, S., Griffa, A., Molcard, A., 2003b. Floating debris in the Ligurian Sea, north-western Mediterranean. Marine Pollution Bulletin 46(9), 1142-1149.

Berline, L., Zakardjian, B., Molcard, A., Ourmières, Y., Guihou, K., 2013. Modeling jellyfish Pelagia noctiluca transport and stranding in the Ligurian Sea. Marine Pollution Bulletin 70(1-2), 90-99.

Barrier, N., Ourmieres, Y. and Petrenko, A., 2016. Intrusions of the Northern Mediterranean Current on the eastern Gulf of Lion: insights from in-situ observations and high resolution numerical modelling. Ocean Dynamics, 66 (3), p 313-327.

Bethoux, J. P., Prieur, L., Nyffeler, F., 1982. The water circulation in the north-western Mediterranean Sea, its relations with wind and atmospheric pressure. In: Hydrodynamics of SemiEnclosed Seas, J. C. J. Nihoul ed, 129-142.

Boucher, J., Ibanez, F., Prieur, L., 1987. Daily and seasonal variations in the spatial distribution of zooplankton populations in relation to the physical structure in the Ligurian Sea front. Journal of Marine Research 45(1), 133-173.

Buckland, S. T., Anderson, D. R., Burnham, K. P., Laake, J. L., Borchers, D. L., Thomas, L., 2001. Introduction to distance sampling. Oxford University Press, p.432.

Buongiorno Nardelli, B., Tronconi, C., Pisano, A., Santoleri, R., 2013. High and ultra-high resolution processing of satellite Sea Surface Temperature data over southern European seas in the framework of MyOcean project. Remote Sensing of Environment 129, 1-16.

Cailleau, S., Fedorenko, V., Barnier, B., Blayo, E., Debreu, L., 2008. Comparison of different numerical methods used to handle the open boundary of a regional ocean circulation model of the 
Bay of Biscay. Ocean Modelling 25(1-2), 1-16.

Conan, P., Millot, C., 1995. Variability of the Northern Current off Marseilles, western Mediterranean Sea, from february to june 1992. Oceanologica Acta 18(2), 193-205.

Cózar, A., Sanz-Martín, M., Martí, E., González-Gordillo, I., Ubeda, B., Gálvez, J. Á., Irigoien, X., Duarte, C. M., 2015. Plastic accumulation in the Mediterranean Sea. PloS ONE 10(4), e0121762.

Derraik, J. G. B., 2002. The pollution of the marine environment by plastic debris: a review. Marine Pollution Bulletin 44(9), 842-852.

Di-Méglio, N. and Campana, I., 2017. Floating macro-litter along the Mediterranean French coast: Composition, density, distribution and overlap with cetacean range. Marine Pollution Bulletin, 118 (1-2), 155-166.

Eriksen, M., Lebreton, L. C. M., Carson, H. S., Thiel, M., Moore, C. J., Borerro, J. C., Galgani, F., Ryan, P. G., Reisser, J., 2014. Plastic pollution in the world's oceans: more than 5 trillion plastic pieces weighing over 250,000 tons afloat at sea. PloS ONE 9(12), e111913.

Reference to be removed?

Ferraris, M., Berline, L., Lombard, F., Guidi, L., Elineau, A., Mendoza-Vera, J. M., Lilley, M. K. S., Taillandier, V., Gorsky, G., 2012. Distribution of Pelagia noctiluca (Cnidaria, Scyphozoa) in the Ligurian Sea (NW Mediterranean Sea). Journal of Plankton Research 34(10), 874-885.

Galgani, F., Souplet, A., Cadiou, Y., 1996. Accumulation of debris on the deep sea floor off the French Mediterranean coast. Marine Ecology Progress Series 142, 225-234.

Galgani, F., Leaute, J. P., Moguedet, P., Souplet, A., Verin, Y., Carpentier, A., Goraguer, H., Latrouite, D., Andral, B., Cadiou, Y., Mahe, J. C., Poulard, J. C., Nerisson, P., 2000. Litter on the sea floor along European coasts. Marine Pollution Bulletin 40(6), 516-527.

Gerigny, O., Tomasino, C., Henry, M., Galgani, F., 2011. Rapport état initial déchets en mer, sousrégion marine $\mathrm{MO}$, p.5.

Gregory, M. R., 2009. Environmental implications of plastic debris in marine settings entanglement, ingestion, smothering, hangers-on, hitch-hiking and alien invasions. Philosophical Transactions of the Royal Society of London B: Biological Sciences 364(1526), 2013-2025.

Guihou, K., Marmain, J., Ourmières, Y., Molcard, A., Zakardjian, B., Forget, P., 2013. A case study of the mesoscale dynamics in the north-western Mediterranean Sea: a combined data-model approach. Ocean Dynamics 63(7), 793-808.

Haller, G., Yuan, G., 2000. Lagrangian coherent structures and mixing in two-dimensional turbulence. Physica D: Nonlinear Phenomena 147(3-4), 352-370.

Haller, G., 2011. A variational theory of hyperbolic Lagrangian Coherent Structures. Physica D: Nonlinear Phenomena 240(7), 574-598.

Haza, A. C., Griffa, A., Martin, P., Molcard, A., Özgökmen, T. M., Poje, A. C., Barbanti, R., Book, J. W., Poulain, P. M., Rixen, M., Zanasca, P., 2007. Model-based directed drifter launches in the Adriatic Sea: results from the DART experiment. Geophysical Research Letters 34(10), L10605.

Herrmann, M., Somot, S., Calmanti, S., Dubois, C., Sevault, F., 2011. Representation of spatial and temporal variability of daily wind speed and of intense wind events over the Mediterranean Sea using dynamical downscaling: impact of the regional climate model configuration. Natural Hazards and Hearth System Science 11, 1983-2001.

Kubota, M., 1994. A mechanism for the accumulation of floating marine debris north of Hawaii. Journal of Physical Oceanography, 24, 1059-1064. 
La Violette, P. E., 1994. Overview of the major forcings and water masses of the western Mediterranean Sea. vol46. P. E. La Violette et al., AGU, Washington, DC.

Lebreton, L. C. M., Greer, S. D., Borrero, J. C., 2012. Numerical modelling of floating debris in the world's oceans. Marine Pollution Bulletin 64(3), 653-661.

Lucia, G. A., Caliani, I., Marra, S., Camedda, A., Coppa, S., Alcaro, L., Campani, T., Giannetti, M., Coppola, D., Cicero, A. M., Panti, C., Baini, M., Guerranti, C., Marsili, L., Massaro, G., Fossi, M. ! C., Matiddi, M., 2014. Amount and distribution of neustonic micro-plastic off the western Sardinian coast (central-western Mediterranean Sea). Marine Environmental Research 100, 10-16.

Madec, G., 2008. NEMO ocean engine. Note du Pôle de modélisation. Institut Pierre-Simon Laplace, p.193.

Mansui, J., Molcard, A., Ourmières, Y., 2015. Modelling the transport and accumulation of floating marine debris in the Mediterranean basin. Marine Pollution Bulletin 91(1), 249-257.

Marmain, J., Molcard, A., Forget, P., Barth, A., Ourmieres, Y., 2014. Assimilation of HF radar surface currents to optimize forcing in the northwestern Mediterranean Sea. Nonlinear Processes in Geophysics, 21, 659-675.

McCoy, F. W., 1988. Floating megalitter in the eastern Mediterranean. Marine Pollution Bulletin 19(1), 25-28.

Millot, C., 1999. Circulation in the western Mediterranean Sea. Journal of Marine Systems 20(1-4), 423-442.

Moore, C.J., Moore, S.L., Leecaster, M.K., Weisberg, S.B., 2001. A comparison of plastic and plankton in the North Pacific Central Gyre. Mar. Pollution Bulletin. 42, 1297-1300.

Moore, C. J., Lattin, G. L., Zellers, A. F., 2011. Quantity and type of plastic debris flowing from two urban rivers to coastal waters and beaches of southern California. Journal of Integrated Coastal Zone Management 11(1), 65-73.

Morris, R. J., 1980. Floating plastic debris in the Mediterranean. Marine Pollution Bulletin 11(5), 125.

Niewiadomska, K., Claustre, H., Prieur, L., d'Ortenzio, F., 2008. Submesoscale physicalbiogeochemical coupling across the Ligurian Current (northwestern Mediterranean) using a biooptical glider. Limnology and Oceanography 53, 2210-2225.

Ourmieres, Y., Zakardjian, B., Béranger, K., Langlais, C., 2011. Assessment of a NEMO-based downscaling experiment for the north-western Mediterranean region: impacts on the Northern Current and comparison with ADCP data and altimetry products. Ocean Modelling 39(3-4), 386404.

Pedrotti, M. L., Petit, S., Elineau, A., Bruzaud, S., Crebassa, J. C., Dumontet, B., Marti, E., Gorsky, G., Cózar, A., 2016. Changes in the floating plastic pollution of the Mediterranean Sea in relation to the distance to land. PloS ONE 11(8), e0161581.

Pettex, E., Lambert, C., Laran, S., Ricart, A., Virgili, A., Falchetto, H., Authier, M., Monestiez, P., van Canneyt, O., Dorémus, G., Blanck, A., Toison, V., Ridoux, V., 2014. Suivi aérien de la mégafaune marine en France métropolitaine. SAMM 1 et 2 - Hiver 2011/2012 et Été 2012. Rapport final Observatoire PELAGIS réalisé dans le cadre du Programme d'Acquisition de Connaissances sur les Oiseaux et les Mammifères Marins -PACOMM, p.169. 
Rubio, A., Arnau, P. A., Espino, M., Flexas, M. d M., Jordà, G., Salat, J., Puigdefàbregas, J., Arcilla, A. S., 2005. A field study of the behaviour of an anticyclonic eddy on the Catalan continental shelf (NW Mediterranean). Progress in Oceanography 66(2-4), 142-156.

Sammari, C., Millot, C., Prieur, L., 1995. Aspects of the seasonal and mesoscale variabilities of the Northern Current in the western Mediterranean Sea inferred from the PROLIG-2 and PROS-6 experiments. Deep Sea Research Part I: Oceanographic Research Papers 42(6), 893-917.

Suaria, G., Aliani, S., 2014. Floating debris in the Mediterranean Sea. Marine Pollution Bulletin 86(1-2), 494-504.

Tallapragada, P., Ross, S. D., 2013. A set oriented definition of finite-time Lyapunov exponents and coherent sets. Communications in Nonlinear Science and Numerical Simulation 18(5), 1106-1126.

Taupier-Letage, I., Millot, C., 1986. General hydrodynamical features in the Ligurian Sea inferred from the DYOME experiment. Oceanologica Acta 9, 119-131.

Thiel, M., Hinojosa, I., Vásquez, N., Macaya, E., 2003. Floating marine debris in coastal waters of the SE-Pacific (Chile). Marine Pollution Bulletin 46(2), 224-231.

Thiel, M., Hinojosa, I. A., Joschko, T., Gutow, L., 2011. Spatio-temporal distribution of floating objects in the German Bight (North Sea). Journal of Sea Research 65(3), 368-379.

Thiel, M., Hinojosa, I. A., Miranda, L., Pantoja, J. F., Rivadeneira, M. M., Vásquez, N., 2013. Anthropogenic marine debris in the coastal environment: a multi-year comparison between coastal waters and local shores. Marine Pollution Bulletin 71(1-2), 307-316.

Topçu, E. N., Tonay, A. M., Öztürk, B., 2010. A preliminary study on marine litter in the Aegean Sea. Rapp. Comm. int Mer Médit 39, 804.

UNEP, 2009, Marine Litter: A Global Challenge. Nairobi: United Nations Environment Programme, p.232.

Vauk, G. J. M., Schrey, E., 1987. Litter pollution from ships in the German Bight. Marine Pollution Bulletin 18(6), 316-319. 


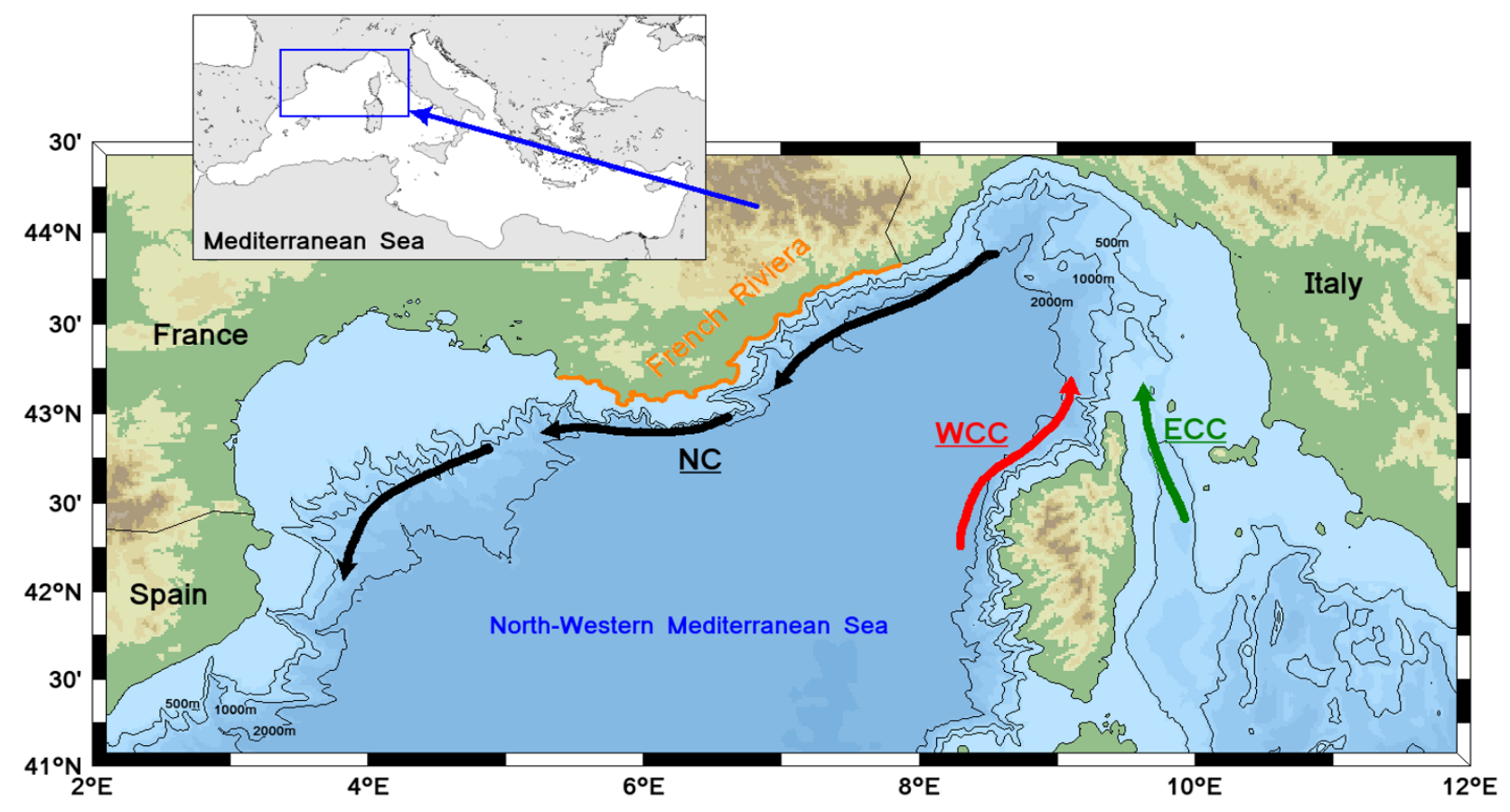

Fig. 1: Map of the north-western Mediterranean Sea. Major surface currents are identified with the acronyms specified in the text and the French Riviera is highlighted by an orange line. 


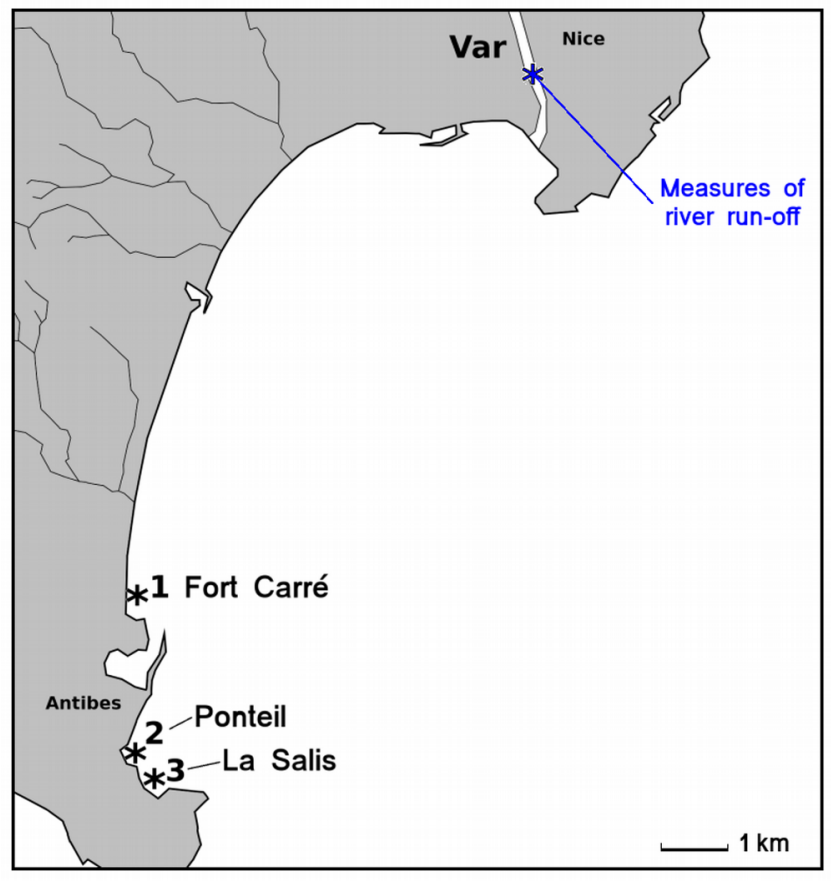

Fig. 2: Location of the three beaches sampled in June 2010 and the Var river. The Var river run-off was recorded at the Napoleon-III bridge station (blue star). 


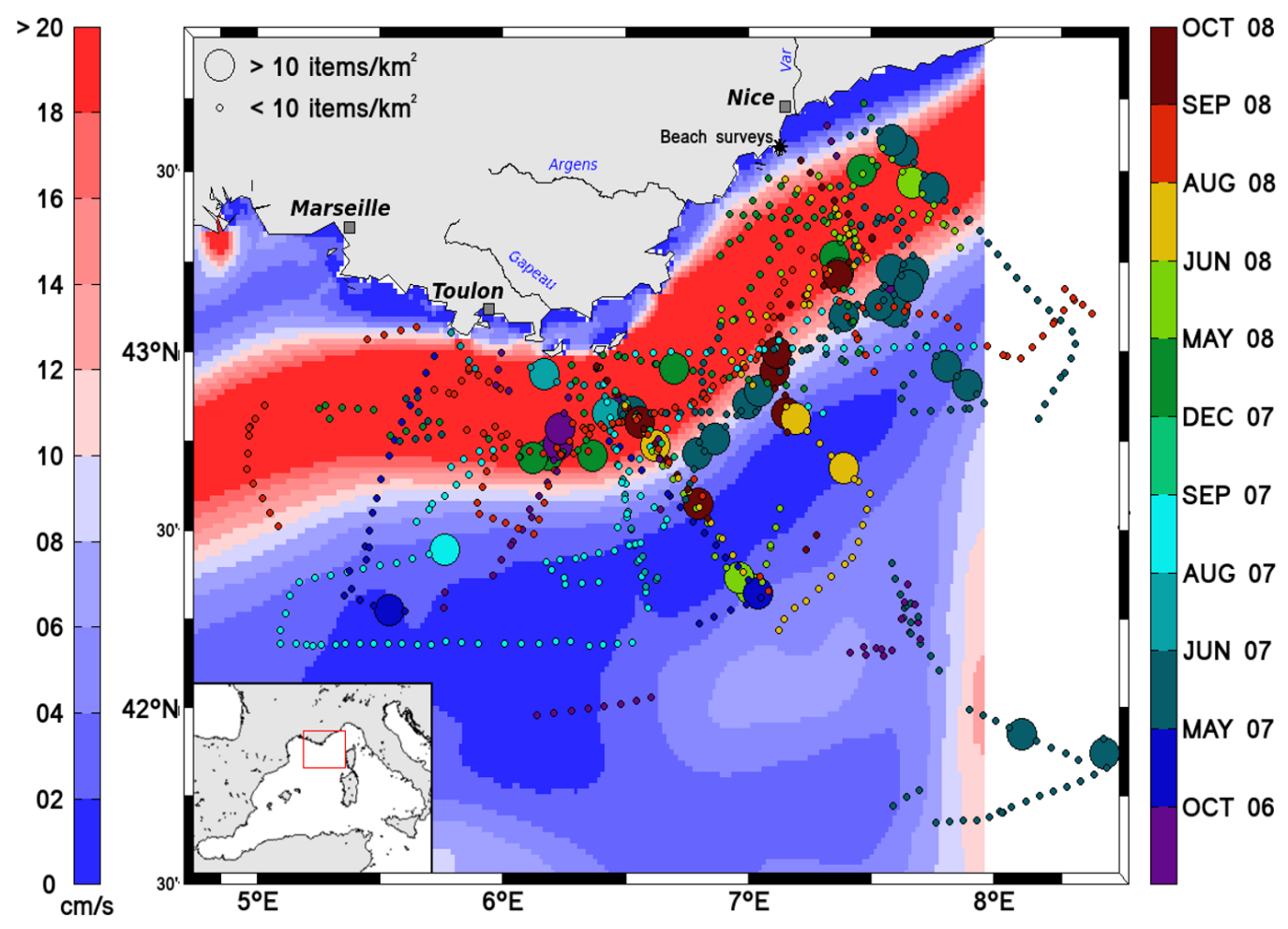

Fig. 3: Map of floating marine litter distribution observed along the French Riviera during the EcoOcean cruises (October 2006 - October 2008). Coloured circles mark the positions and dates of shipboard surveys. Debris densities are broken down in two categories in order to highlight the position of high values: low densities ( $<10$ items $/ \mathrm{km}^{2}$, small circles) and high densities ( $>10$ items $/ \mathrm{km}^{2}$, large circles). The NC general path was determined from GLAZUR64 surface mean velocity fields. Black star denotes the location of the beach surveys in Antibes (June 2010). 


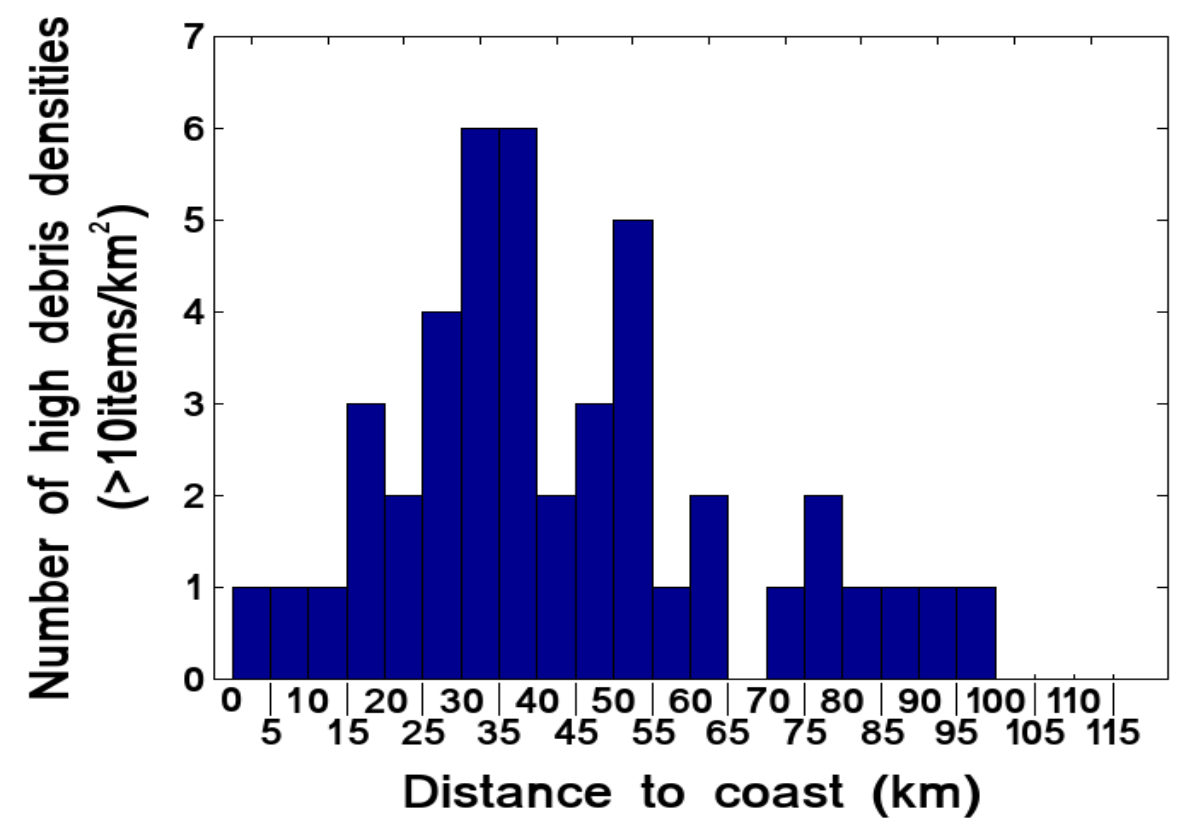

Fig. 4: Number of debris high densities $\left(>10\right.$ items $/ \mathbf{k m}^{2}$ ) observed during shipboard surveys in relation to the distance to the coast. We considered spatial ranges of $5 \mathrm{~km}$, from 0 to $115 \mathrm{~km}$, to count the number of high debris densities. 

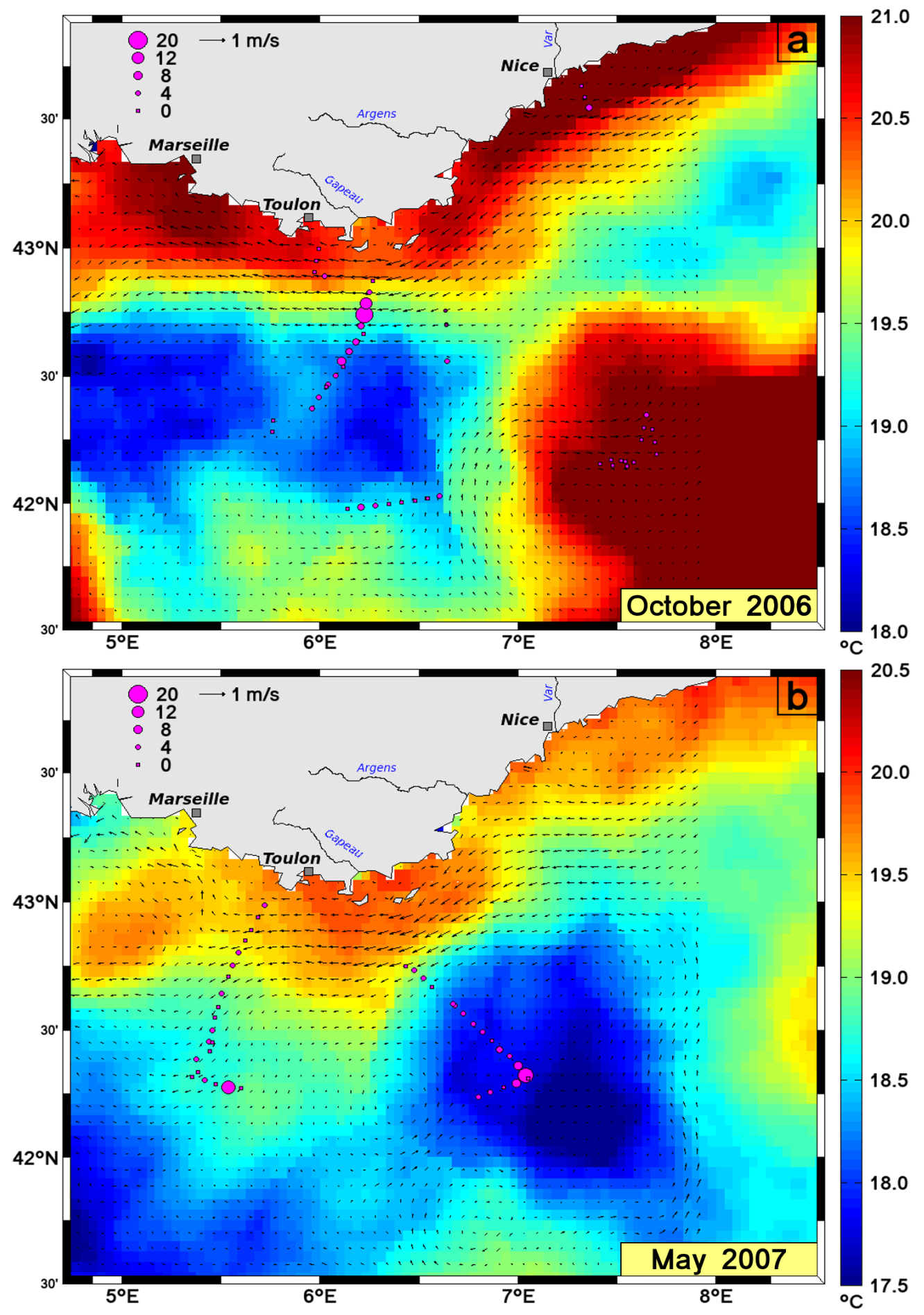

Fig. 5: Floating marine litter distribution observed on October 2006 (a) and May 2007 (b). The mean surface velocity was calculated by averaging daily modelled velocity fields of the upper vertical level on October 8 to 12 for (a), and May 23 and 24 for (b). In both cases, SST maps are rather similar for each period of floating marine debris observation, and only SST maps on October 10 (a) and May 23 (b) were superimposed to surface velocity fields and debris survey locations. 

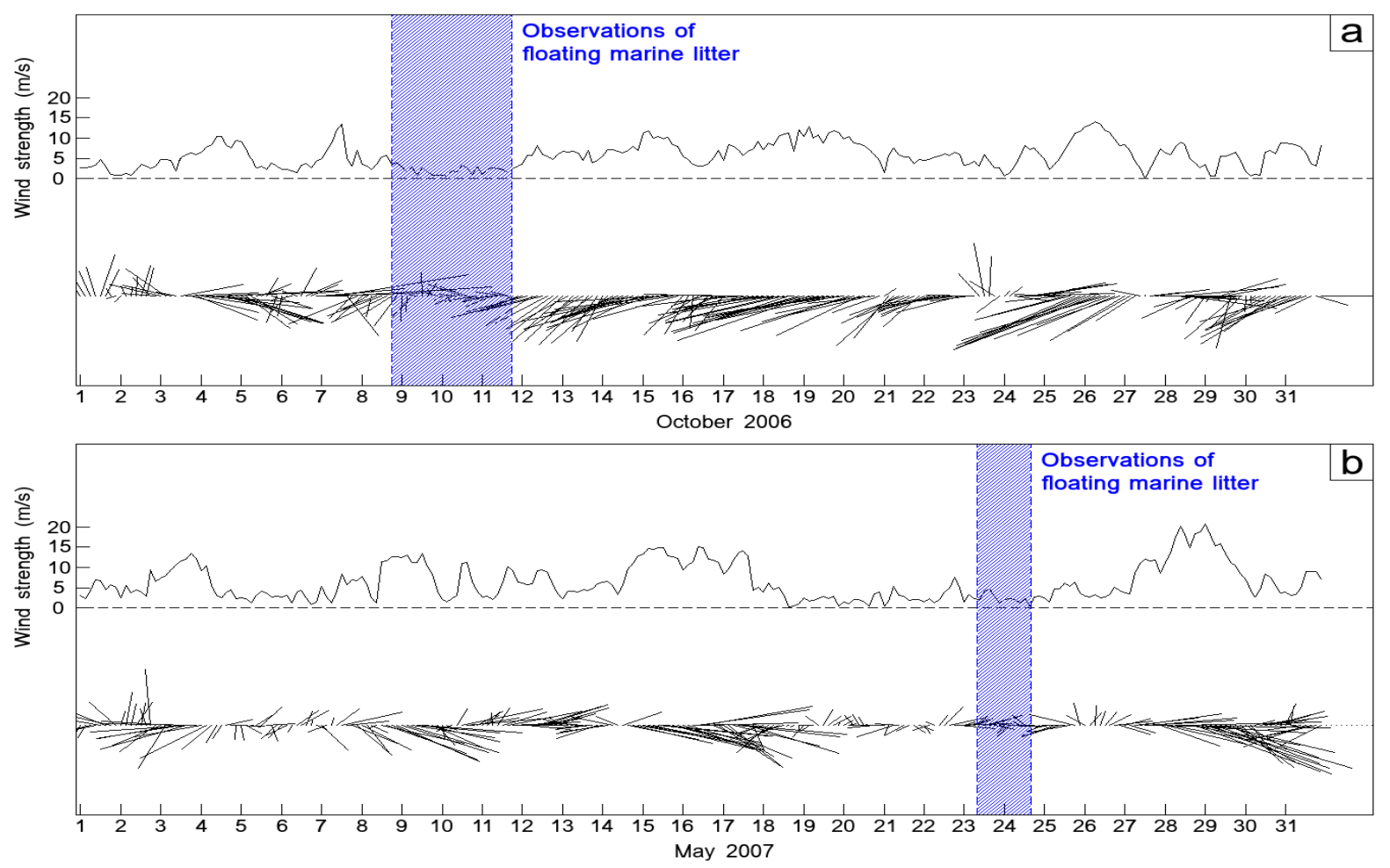

Fig. 6: Stick diagram of ALADIN wind speed in October 2006 (a), and May 2007 (b). The direction of the upward (downward) sticks is North (South). The diagram was plotted at the $43^{\circ} 02 \mathrm{~N}-6^{\circ} 46 \mathrm{E}$ location (nearest shore position representative of the mean wind regime). Since it is difficult to provide a direct estimation of the wind speed on the stick diagram, the wind magnitude has been plotted above for the two cases.

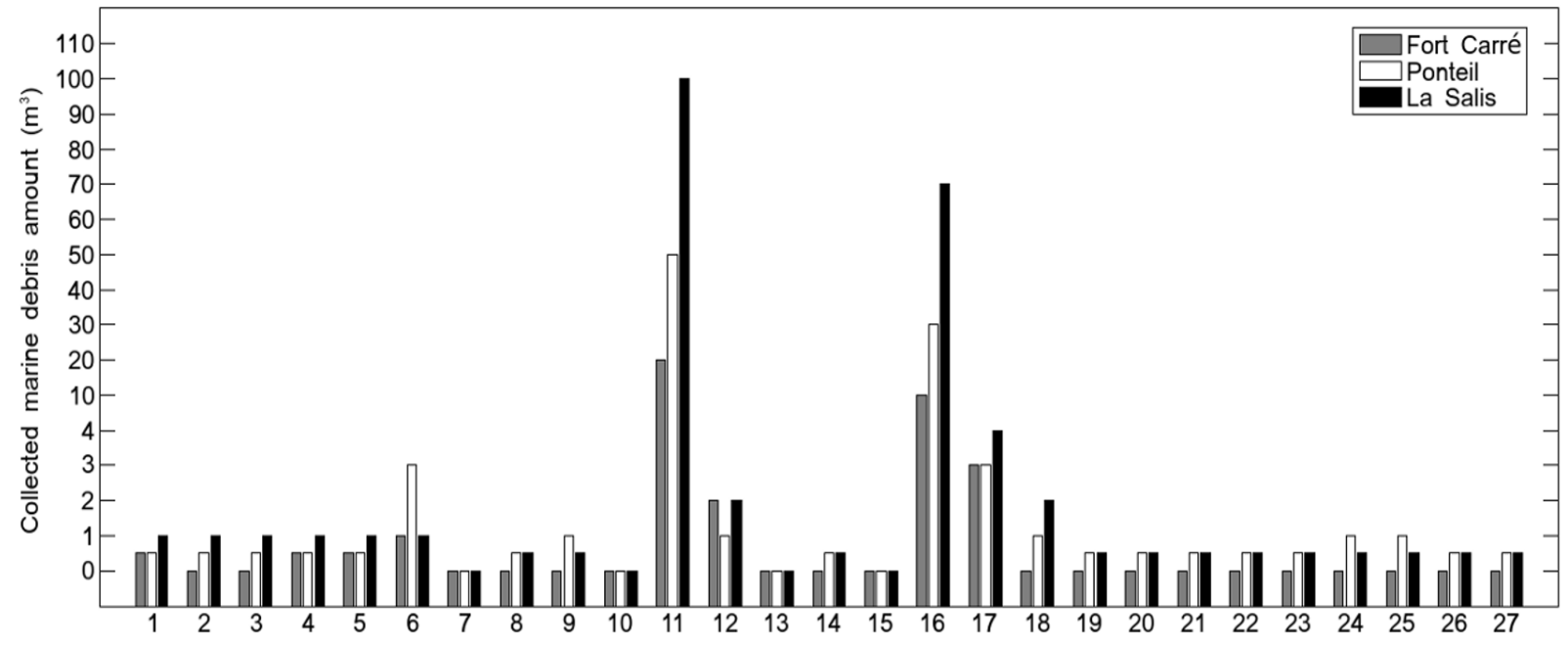

Fig. 7: Debris volume levels collected on three beaches of Antibes $\left(\mathrm{m}^{3}\right)$ in June 2010: (grey) Fort Carré, (white) Ponteil and (black) La Salis. 


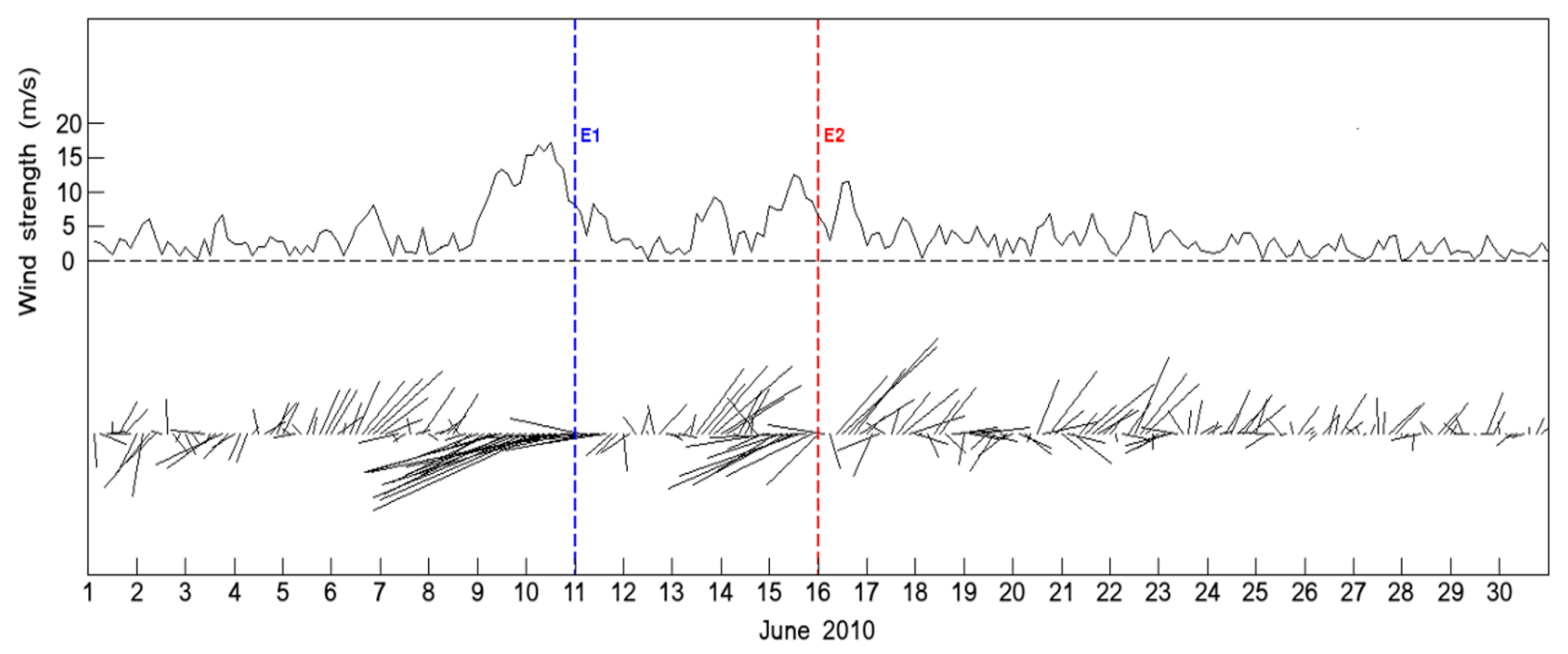

Fig. 8: Stick diagram of ALADIN wind speed at Antibes location (43 $\left.{ }^{\circ} 60 \mathrm{~N}-7^{\circ} 10 \mathrm{E}\right)$. E1 (June 11) and E2 (June 16) stranding events are respectively indicated by blue and red dotted lines.

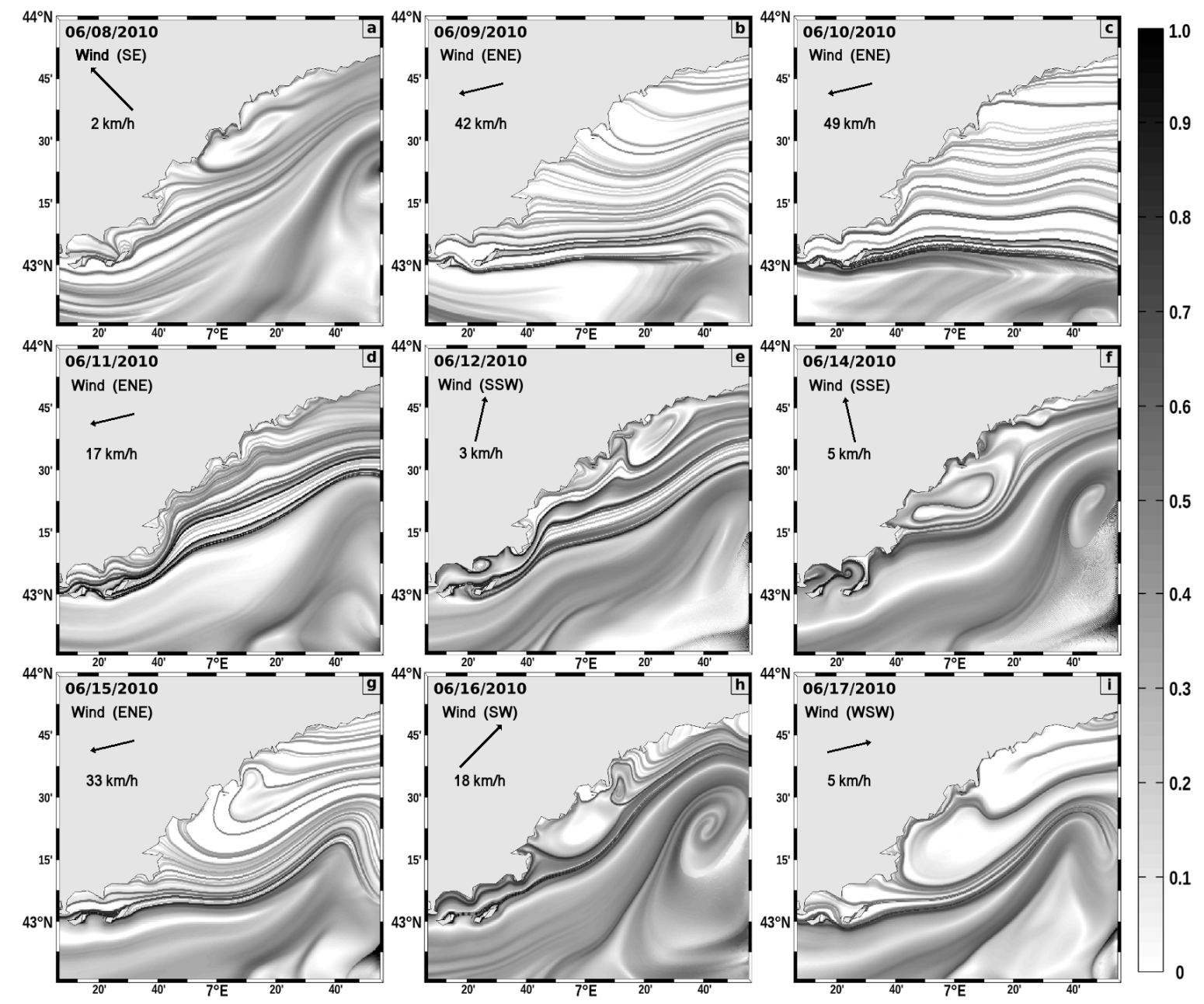

Fig. 9: Snapshots of FTLEs forward in time from June 8 to 17, 2010. Each FTLE field was based on a 6day integration time and a tracer resolution of $1 / 256^{\circ}$. Black arrows show the main wind direction for each day, and numbers below refer to mean wind speed. 


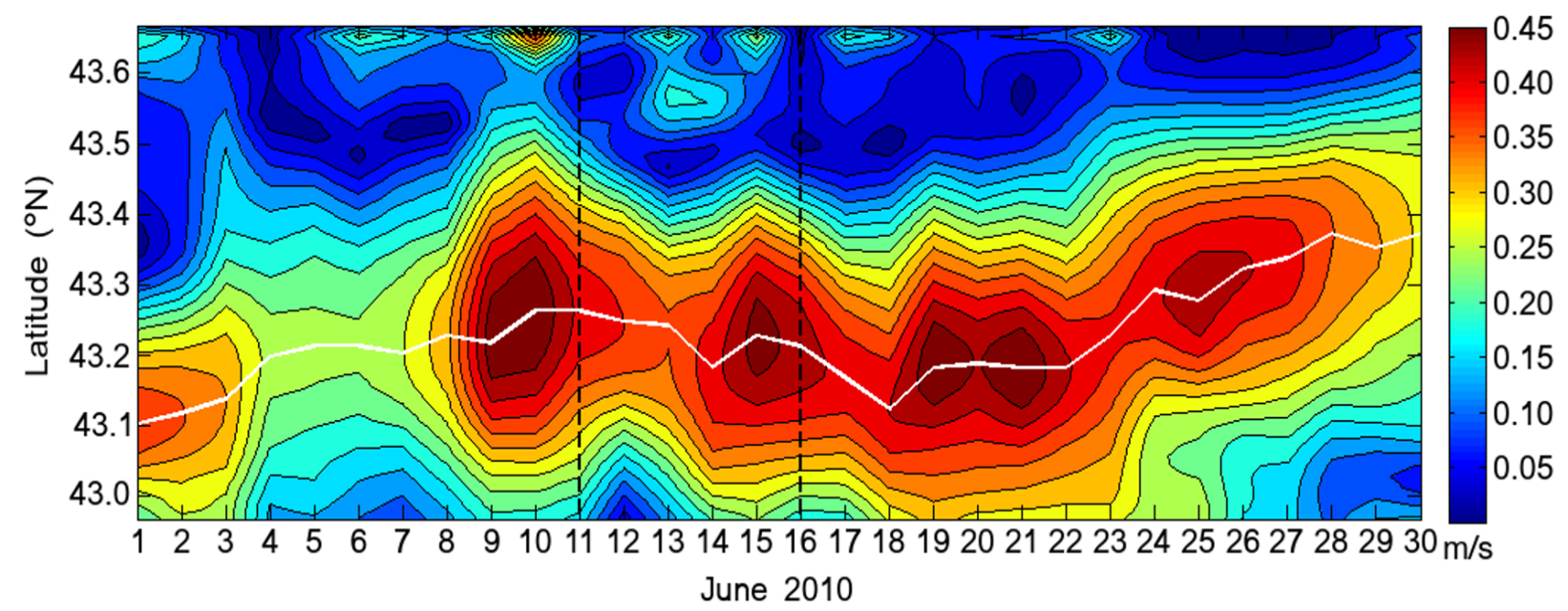

Fig. 10: Time-latitude diagram of the GLAZUR64 modelled upper layer velocity field along a $7^{\circ} 23.44$ section. For each latitudinal section, a current core location (white line) is defined as the position where the current is maximum.

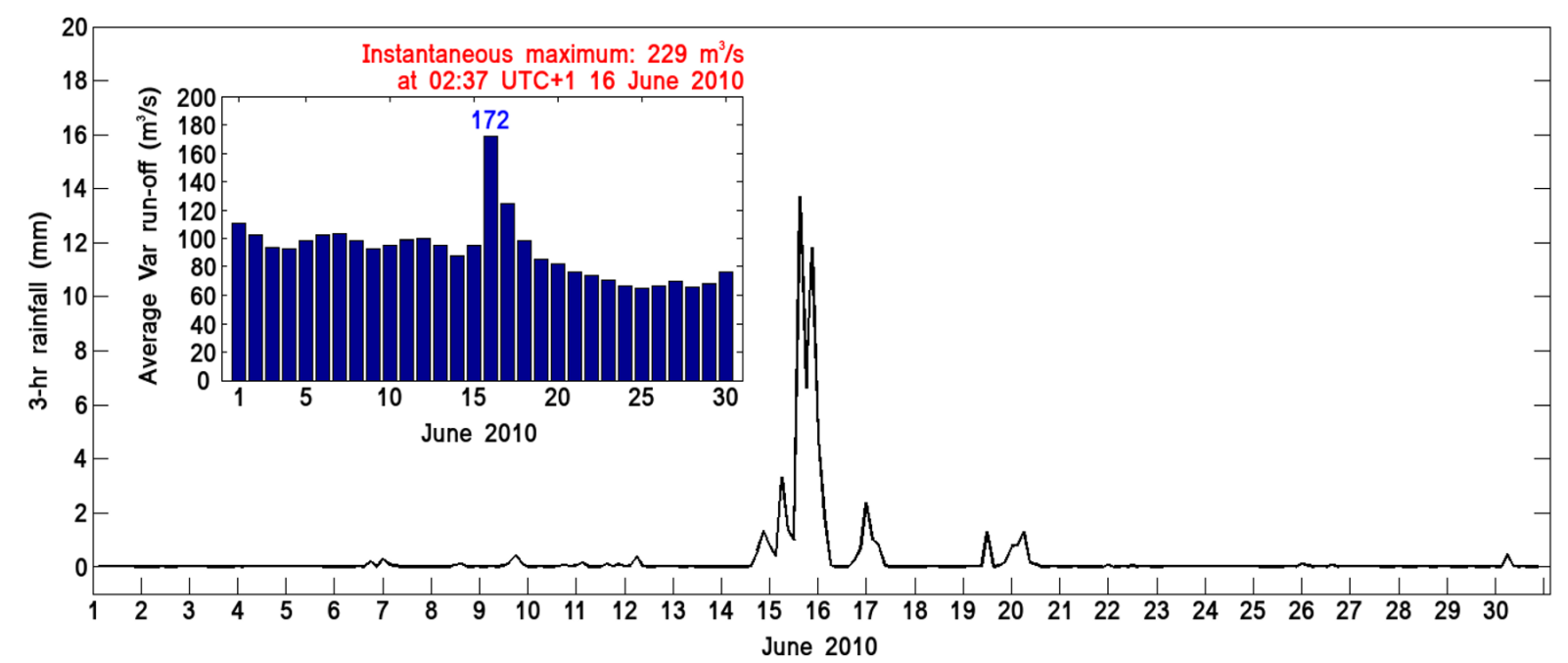

Fig. 11: 3-h rainfall from the ALADIN model at Antibes location $\left(43^{\circ} 60 \mathrm{~N}-7^{\circ} 10 \mathrm{E}\right)$, presented with daily run-off of the Var river (embedded figure) in June 2010. 